\title{
A never-born Russian-language earth globe in the Virtual Globes Museum
}

\author{
Dávid Gerzsenyi ${ }^{\mathrm{a}, *}$, Gábor Gercsák ${ }^{\mathrm{a}}$, Mátyás Márton ${ }^{\mathrm{a}}$ \\ ${ }^{a}$ Institute of Cartography and Geoinformatics, Eötvös Loránd University, Hungary, 1117 Budapest, Pázmány Péter sétány 1/A, \\ gerzsd@student.elte.hu,gercsak@map.elte.hu,matyi@map.elte.hu
}

* Corresponding author

\begin{abstract}
:
It has been just for more than thirty years that the English-language version of the detachable structural-morphological globe of the Earth with $40 \mathrm{~cm}$ diameter produced by the Cartographia Enterprise won the prize of the best demonstration aid (Anson and Gutsell 1989) at the Budapest conference of the International Cartographic Association in August 1989. This success was the result of the cooperation between two education institutions (Kossuth Lajos University and Eötvös Loránd University /ELTE/) and two Hungarian firms (Cartographia Enterprise and School Equipment Producing and Marketing Company). This unique product has been the only thematic earth globe designed and published in Hungary and which was duplicated in a relatively large number. It is a rarity today. This is one of the reasons why this globe has been placed in the Virtual Globes Museum (VGM) (http://terkeptar.elte.hu/vgm). This paper gives an overview of the history of these thematic globes: the Hungarian versions made in 1986 (VGM ID 8, 9, 10) and the English versions published in 1988 (VGM ID 66, 67, 68). It introduces the immediate scientific antecedents of their birth and - being a demonstration aid - the process of publishing. The paper also presents the work with the Russian version of the globe carried out at the Institute of Cartography and Geoinformatics, ELTE (VGM ID 154, 155, 156). This will lead to the expansion of the number of globes in the VGM. The close relationship between the new product and the former two editions is also pointed out.
\end{abstract}

Keywords: map history, history of technology, earth globes, Virtual Globes Museum
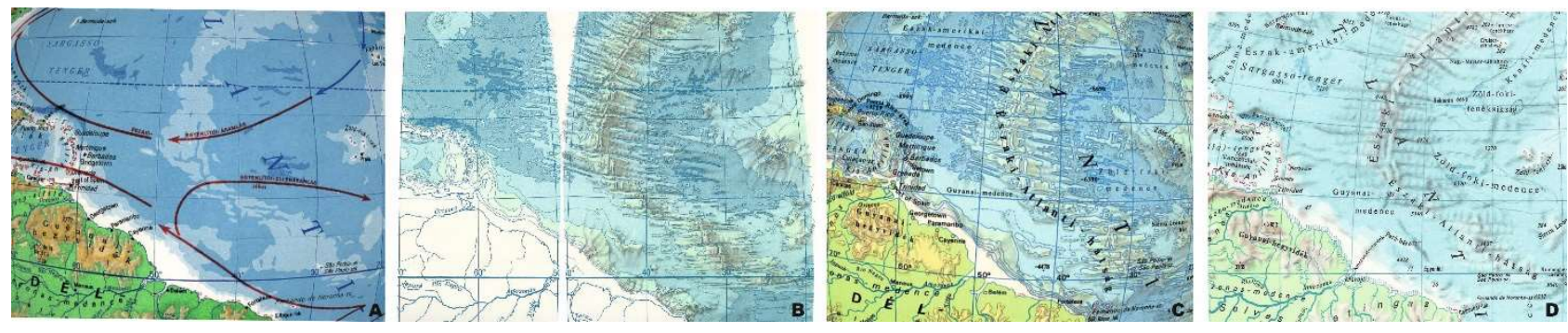

Figure 1. The same area of the Atlantic Ocean (A) on the $40 \mathrm{~cm}$ educational globe (1981) (VGM ID 84), (B) on the sample processing (1984), (C) on the $25 \mathrm{~cm}$ globe (VGM ID 41), and (D) in the Nagy Világatlasz (Great World Atlas) of Kartográfiai Vállalat [Cartographia] (1985).

\section{Antecedents}

The research paper, "Study on the representation of seafloor relief" was published at the Cartographia Enterprise in Budapest in 1984 (Márton and Kővári 1984). It had two A3-sized annexes, which showed the sample processing of four spherical segments (gores) in the projection of the $40 \mathrm{~cm}$ diameter earth globe (Figure $1 \mathrm{~B}$ ). When these maps were compared with the relief representation of undersea features on the $40 \mathrm{~cm}$ educational relief globe published as a demonstration aid for schools in 1962 (VGM ID 43) and renewed in 1981 (VGM ID 84), it was clear that the latter products were outdated (Figure $1 \mathrm{~A}$ ).
The sample processing aiming at creating a new and modern representation of undersea relief was made at the Editing Division 2 of Cartographia, edited by Mátyás Márton, designed by József Kővári, hill shading by Márta Bárkainé-Neményi, fair drawing by János Bakos and Gyula Gyenes. The sheets were printed at the Duplicating Division.

As there were no computers in use that time for the task at Cartographia, the transformation of a projection was a most labour intensive and time-consuming job: the publishers did not think it important to re-edit the map content from one projection to another. They rather spent time on finding a larger-scale source map than the target scale but made in the same or nearly the same projection. 
The sources of maritime themes - including the representation of depths - were usually maps in Mercator's conformal projection. Therefore, it was impossible to avoid projection transformation: the bathymetric contour lines had to be drawn from the spherical trapezoids of the source map onto the target map.

As usually, students of cartography from the Department of Cartography of ELTE came to the Editing Division 2 of Cartographia to do their summer practice at the end of their fourth year of studies in 1985. (In those times, cartography training lasted for five years.) Based on the results of his research, Mátyás Márton guided the students. They prepared the preliminary layout of the undersea relief for the whole oceans and seas at $1: 10$ million equatorial scale using the map series of the General Bathymetric Chart of the Oceans (GEBCO) as source. The sample processing was derived from these maps, which already contained the bathymetric contours selected to be depicted in the spherical ("distortion-free") projection. This "analogue database" served as source map for the preparation of undersea relief maps at Cartographia.

First, the layouts of the $25 \mathrm{~cm}$ relief globe were prepared at the Editing Division 2 (Figure $1 \mathrm{C}$ ) on the order of the Foreign Trade Department of Cartographia. However, there were foreign demands for the $25 \mathrm{~cm}$ relief globe in Hungarian, English, German and Czech language mutations ${ }^{11}$ in addition to the political globe at the same scale made in Hungarian, German and Czech (later also in Polish). It is worth noting here that Cartographia made about 600 thousand (!) globes between 1963 and 1990, out which 100 thousand (!) foreign-language copies were exported (Kovács and Márton 1989).

This is the way how the most modern Hungarian terrestrial and undersea relief globes were born at Cartographia. The detailedness of the representation of undersea relief on the globes was far better than on the ocean maps of the same scale in the completely newly edited Great World Atlas (1985) just before publishing (Figure $1 \mathrm{D}$ ). It has to be noted that hill shading added a lot to the picture of maps in the atlas (the hypsometric layers were at the depth zones 0 , $-200,-2000,-4000,-6000,-8000$ metres).

The isolines of the new $25 \mathrm{~cm}$ relief globe made in four language mutations - which were also published in print ran at 5000, 3000, 1500, 1000, 500, 200, 0, (depression), $200,-1000,-2000,-3000,-4000,-5000,-6000,-7000$ $\mathrm{m}$. If necessary, the isolines over the seas were completed with auxiliary (bisecting and quadrisecting) bathymetric contours. Uniform hill shading of hypsometric layers was used - over the continents and the seas (!) - to achieve a picturesque image of the relief. A greenish shade in two grades was also introduced for certain areas by "adding" $10 \%$ and $20 \%$ pale yellow colour. This slightly broke the

\footnotetext{
${ }^{1}$ Mutations: Globes, hand maps, atlases (and other publications) made in foreign languages but with identical map content. These products were all printed in colours in the same run, but the black colour - usually the content of labelling and annotations - was different, that is "mutated". This explains why their printing was most economical. In such cases, the
}

blue colour of the depth zones between 2000-3000 and 3000-4000 metres in sea and ocean areas. This method broke with the former practice by highlighting the lower levels of the ridges and continental slope. In this way, the large structural units of the oceans (continental shelfs, deep-sea areas and ridges) could be excellently depicted. Eight colours were used for printing: dark blue, light blue, light yellow, grey, black, red, brown and green (Figure 2).

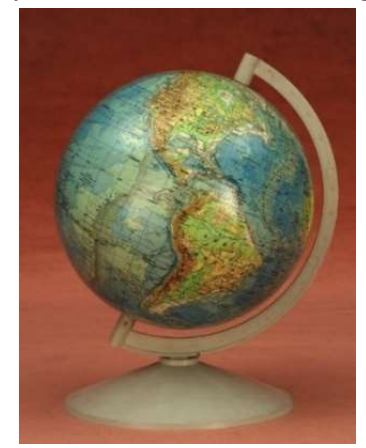

Figure 2. Picture of a $25 \mathrm{~cm}$ relief globe (Photo by Zoltán Nemes). The mutations in the "family" can also be seen in the VGM: ID 41 (Hungarian), ID 75 (English), ID 5 (German), ID 64 (Czech).

The key contributors deserve mentioning here too. The globe was made at the Editing Division 2 and the Cartolithographic Division in 1985-1986, edited by Mátyás Márton, designed by József Kővári (relief drawing) and Piroska Mészáros (labelling), hill shading done by Kálmánné Tóvizi, fair drawing and lithography by László Nagy, printing by the Duplicating Division, mounting by the Globe Group of Cartographia and Texgráf firm.

\section{Production history of an educational demonstration aid in Hungary in the mid-1980s}

The traditional method of making globes, which was developed in historical times, was still in use in the 1980s: the gores of $20^{\circ}$ to $30^{\circ}$ width were printed on paper, then they were mounted (glued) on the surface of the globe (usually made of plastic).

Dr. Lajos Hajdu, a geography teacher in the demonstration school of Kossuth Lajos University (now the University of Debrecen) submitted a proposal to TANÉRT, a firm that produced and traded school equipment, in 1984. The educational material, "Detachable Earth model", took over the representation of the oceans from a $40 \mathrm{~cm}$ educational globe and showed the structural-morphological content over the continents. All this was completed with showing the boundaries of the lithospheric plates of the Earth. The body of the globe could be detached into pieces, and their inner sides illustrated the inner structure of the Earth with profiles and graphs explaining the physical parameters of the planet.

necessary copies were printed e.g. in Hungarian, then only the printing plate containing the Hungarian labels had to be replaced by the English-language plate of labels. The labels in further foreign languages were used for printing in the same way. 
Pál Kovács, responsible editor, offered a price, which was approved by Tibor Dudar, editor in chief, on 10 October 1984. This suggests that TANÉRT had already contacted the Cartographia Enterprise in the matter of making the map prints for the globe. Then followed the usual administration of introducing a new educational material. The representatives of the National Pedagogic Institute and other professionals had a meeting in TANÉRT on 16 April 1985, and they recommended the production of the globe to the Committee on Demonstration Aids. This committee had a meeting on 4 June 1985, which recommended the authorization of purchasing and using the "Detachable Earth model" educational material.

A professional meeting was held on the ordering of the prints of the maps and figures of the detachable globe at Cartographia on 23 October 1985. The agreement said:

- Dr. Lajos Hajdu, innovator, will add further place names on the map and will prepare the names in Hungarian, English and Russian.

- The undersea relief will be represented in the most modern cartographic method. (This point was recommended by Mátyás Márton, geophysicistcartographer, who was appointed leading editor of the work. He supported the work by presenting two A3-sized sample sheets of his research, "Examination of representing undersea relief", and compared them with the sketchy representation of the undersea relief on the $40 \mathrm{~cm}$ educational globe.).

The English-language geographical names were checked and approved in November 1985, the Russian-language names were professionally and linguistically checked and approved in Moscow in March 1986.

There was a small meeting at Cartographia on 8 April 1986, in which the participants were Dr. Lajos Hajdu, Pál Kovács and Mátyás Márton. Several important decisions relating to and modifying the content of the globe were brought here on the suggestion of Márton:

- Dr. Lajos Hajdu will send the explanatory text to the use of the globe in one manuscript copy to Cartographia.

- Considering that TANÉRT modified the cutting of the globe into pieces - probably due to production reasons (but they informed about it only Cartographia and not the innovator)-, Cartographia will re-edit the profiles. In compliance with the new situation, the plate tectonic equatorial profile of $90^{\circ}$ will cover an area of $180^{\circ}$ between the longitudes $10^{\circ}$ East and $170^{\circ}$ West. In this way, the active and passive continental margins will be better emphasized. The thematic content of the globe profile has to be edited so that it should be related to the content presented on the surface of the globe. It followed that the figures showing the physical parameters (velocity of waves, pressure, density) inside of the Earth have to be relocated to opposite the plate tectonic profiles, on the "bottom" of the northern hemisphere. It was also in the agreement that the legend will be placed on the surface of a globe profile that does not include any thematic content. - Cartographia will use the new method to represent the undersea relief according to the negotiation held on 23
October 1985. Cartographia suggests that such contour lines and hill shading should be used also over the continents (as a background image in reduced grey) that do not disturb the thematic content. However, if this solution comes out disturbing on the proof-prints, this might be omitted.

- Dr. Lajos Hajdu accepts that Cartographia will correct minor inaccuracies in the thematic content (e.g. the plate boundaries).

Cartographia planned to use the fair-drawings of the $25 \mathrm{~cm}$ relief globe in 1.63 magnification for the preparation of the map prints. The editing-designing already went on in full speed.

TANÉRT delivered three samples of the detachable globe to Cartographia on 22 September 1986. In the next step, Cartographia prepared prints on various papers with different stretching properties for the trial mounting at TANÉRT. The maps were compiled from the $163 \%$ magnified drawings of the $25 \mathrm{~cm}$ globe in May. That paper was selected that showed acceptable stretching on 31 October.

The proof-prints were carried to TANÉRT by a deliverer. János Győri, director of the production unit, sent a letter to the editor in chief of Cartographia on 11 December saying that "The enclosed returned proof-print can be produced with the change in the colophon". Now the printing machines started to work...

The task of mounting, lacquering, wrapping and trading belonged to TANÉRT.

\section{The Hungarian version of the $40 \mathrm{~cm}$ detachable Earth model}

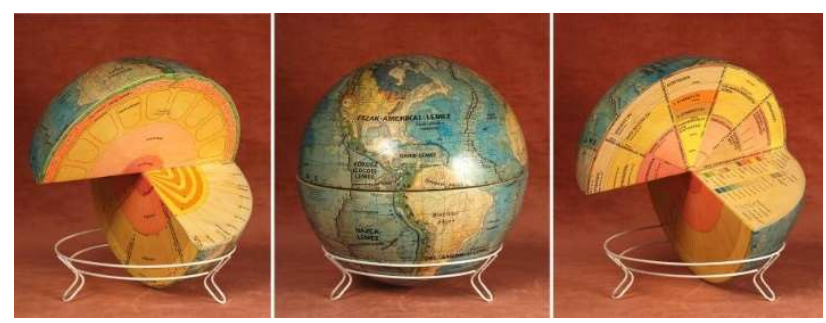

Figure 3. The Hungarian version of the globe fit together and detached (Photo: Zoltán Nemes). The same in the VGM: ID 9, ID 10, ID 8 .

Until this point, the paper described the protocol of producing a product when the order came from outside. In the following, the paper reviews the cartographic tasks with this globe, which brought several challenges.

The supporting globe was born after long negotiations and brainstorming. The original idea included two half globes that can be placed on each other, and the liftable spherical shells from one of them would have illustrated the structure of the Earth. In this case, several liftable elements should have been produced, which would have made the demonstration aid fairly volatile. The technological aspect of the production of the final solution was very simple. Only one type of element had to be produced: two pieces of a quarter of a globe, which had to be glued after turning one of them by 90 degrees. This special-form half-globe made up the supporting globe, which could be placed into 
a three-legged basket made of 5-mm diameter steel wire painted in white (Figure 3). The segments (gores) of the globe map were mounted on the outer surface of the globe, while the surfaces inside the globe were used to illustrate the inner structure of the Earth by figures and profiles showing the physical properties of the Earth.

The simple production of the supporting globe, however, made the cartographic editing difficult and particularly complicated the mounting! The prints of the globe included 6 gores from pole to pole, $2 \times 6$ half-gores extending to the North Pole and the South Pole, and $2 \times 2$ polar caps (with $10^{\circ}$ polar distance) cut into a $90^{\circ}$ and a $270^{\circ}$ sector. The mounting of all these pieces required special attention. The task of mounting the maps meant to perfectly fit the 30 (!) surface elements (6 complete gores $+6 \times 2$ half-gores $+2 \times 2$ polar caps +8 profiles $)-$ in contrast, the traditional mounting included 14 pieces only (12 gores +2 polar caps). The editing and mounting of the profiles with thematic content placed onto the inner surface of the parts of the detachable globe did not ease the work either.

The globe map covering the surface of the globe shows structural-morphological topics, while the representation of the undersea relief (with layered depth zones) is identical to the map of undersea relief on the $25 \mathrm{~cm}$ physical-geographical globe. The relief is illustrated with contour lines in reduced grey that do not disturb the thematic content on the continents, and with bathymetric contours in dark blue over the seas. The expressiveness of the relief is helped by hill shading in grey, which is uniform on the complete (continental and sea) surface of the Earth. The globe shows the lithospheric boundaries in uniform legend for the whole Earth, making distinction between the convergent, divergent and transform (sliding) plate boundaries. The exquisite representation of depths clearly supports the thematic content of plate tectonics and raises attention to the relationship between the structure and morphology (e.g. the development of the central troughs of ocean ridges along the margins of divergent plates, faults along the margins of sliding plates, or the development of trenches at the boundaries of convergent lithospheric plates, etc.).

Information on the inner structure of the Earth can be seen on the profiles if the globe is detached. First profile: theories on the inner structure of the Earth from Suess' model (1896) to the Hungarian Egyed's astrophysical model (1955). Second profile: travelling speed of seismic waves, changes in the pressure and density from the surface to the centre of the Earth. Third profile: changes in the temperature and chemical composition, various boundary surfaces - detected by seismic tests -, and shows a scale model of the inner structure (lithosphere, asthenosphere, mesosphere, etc.) related to the plate tectonic model from the surface to the centre of the planet. Fourth profile: illustrating the relationships between the central angles of the globe (as a geometrical body) and the location of the geographical latitudes. Fifth profile: the model of plate tectonics again (at the plane of the Equator, with depth-distortion to the mesosphere) so that the situations shown in the profile can be unambiguously related to the image of the continental relief on the globe map. It is easy to perceive the thickening of the crust under continents, the relationship between the subducting ocean plate under the continents and the development of trenches as well as of volcanism on continents, etc. Sixth profile: the legend. Further profiles are like questions to test what was learnt (identical profiles without labels and annotations).

The globe map was printed in eight colours: black, dark blue, light blue, brown, pale yellow, yellow, red and grey. The profiles were printed in six colours: black, red, orange, yellow, magenta and green.

A short sum-up of the major actors in the cartographic execution: the $40 \mathrm{~cm}$ detachable structural-morphological Earth model was made at the Editing Division 2 of Cartographia in 1986, with the use of Dr. Lajos Hajdu's innovation, on the order of TANÉRT. Leading editor: Mátyás Márton. Designer: Balázs Kovács (thematic content on continents and seas). Fair drawing: Anna Agárdi. Lithography: Anna Agrádi, Zsuzsa Balla, Mátyás Márton, Borbála Nagy (with use of the materials of the 25 $\mathrm{cm}$ globe). Printing was done at the Duplicating Division of Cartographia, mounting was done by TANÉRT. The globes came on the market in 1987.

\section{Some words on the English edition}

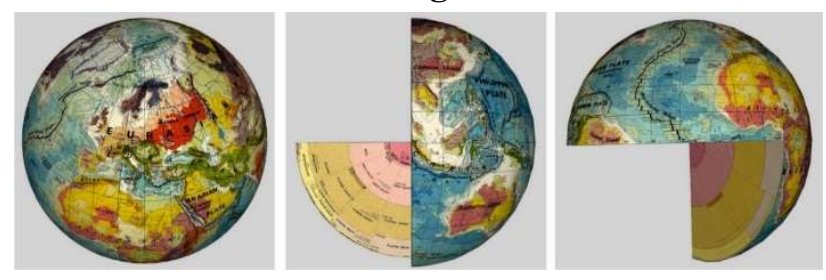

Figure 4. English-language versions of the globe in the VGM: ID 68 (complete), ID 67 and ID 66 (two halves).

The professional and linguistic checking of all place names in English and Russian was completed during 1986; the geographical names of the globe map and the annotations on profiles were also completed. In spite of all this, Cartographia received no order from TANÉRT to continue the work. Only the mutation (version) of the names and annotations in two more languages should have been added: everything, the complete coloured material was already available, because the whole processing considered and prepared for the possibility of parallel printing in colours.

It was in 1988, when Cartographia received an order for the preparation of the English version only (Figure 4). In the absence of Mátyás Márton, the English-language mutation was made under another leading editor, Lászlóné Bardócz. 

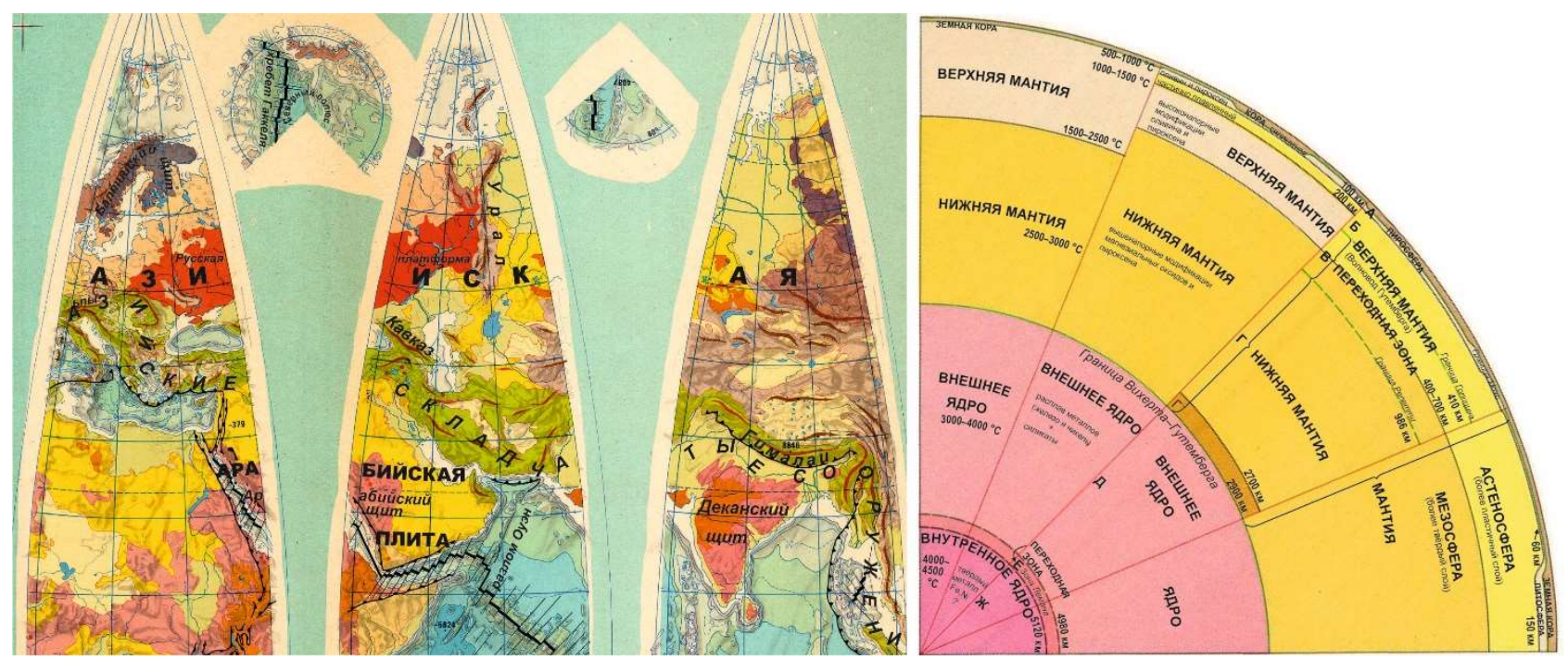

Figure 5. The Russian-language globe, parts of its gores and a profile. VGM ID 154, 155, 156.

This version of the globe brought international recognition to Hungarian cartography! The International Cartographic Association held its bi-annual conference in Budapest in the next year. This was a successful meeting with more than 800 participants in bright August. In parallel with the conference, an international map exhibition was organized in the Buda Castle, where the displayed products were rewarded in nine categories. Hungarian products won in two categories, and of them - in the category of demonstration aids - was the English version of the Earth model (Anson and Gutsell 1989).

\section{On the Russian-language virtual globe}

The linguistic and professional checking of the Russianlanguage material was already done in 1986. Being an educational aid, the names were strikingly written so that they should be legible from a distance too.

In order to place the Russian annotations, a base layer without annotations was needed. Such a layer was not available, therefore, it had to be prepared using the available materials. The base layer was prepared by reworking the scanned English-language prints of the globe. While there are more or less automatic procedures for removing objects from images and restoring the background, these procedures were not very well applicable for the scanned globe prints. The first reasons for this were the inhomogeneous colours and textured look of the coloured areas on the scanned images. Secondly, the waterways and isolines could not be accurately interpolated between the edges of the filled spaces with automatized tools. Therefore, the English text had to be manually removed from the images to prepare a base layer for the Russian annotations.

The goal of the annotation removal was to restore the areal and line features covered by the letters. As the scanned prints showed some wear in certain places, the abraded areas had to be filled. The drawing order of the added features had to be decided to match the layer hierarchy of the original print. The drawing order from bottom to top was the following:

1. Areal features,

2. Border lines of the areal features,

3. Waterways,

4. Isolines,

5. Folds, rifts, plate boundaries,

6. Graticules.

The restoration work was mostly done with Photoshop tools. The Clone Stamp tool was used to restore the areal features and the thicker line features of the image. This tool copied pixels from a predefined part of the image to the selected part. In this case, the possible pattern under the character to be removed was estimated, and the space was filled with pixels of nearby features from the same legend category. More than one pattern had to be used for the same areal feature in order to preserve the hill shading too in certain areas. The thinner line features (border lines, isolines, waterways, and graticules) were restored with curves of appropriate colour and width.

The careful removal of the English annotation and the restoration of the features under its letters created a suitable base layer for the Russian version of the tectonic globe. After placing the Russian annotations on the restored base, the virtual $3 \mathrm{D}$ version of the globe was prepared and uploaded to the repository of the Virtual Globes Museum. Eventually three separate virtual globes were prepared for the museum: one for the full outer layer (VGM ID 154) of the globe and two for the two half globes (VGM ID 155, 156). First, the images of the gores and the polar caps were georeferenced, and the georeferenced images were reprojected to Plate Carrée projection. Then, the textures created from the reprojected images were draped over the virtual globe (Figure 4, left side) and half globe parts (Figure 4, middle and right side). The process of creating traditional virtual globes and globe parts is 
described in detail by Gede and Márton (2009), Gede and Ungvári (2011), and Gede (2015).

Finally, a unique Russian-language globe was created, whose place names and other labels rested in the drawer of a desk for more than thirty years, while its embodied Hungarian and English brothers slowly "die out" in the meantime; they can only meet their Russian "younger brother" in the Virtual Globes Museum (Figure 5).

\section{Acknowledgement}

The authors thank Zsuzsanna Ungvári, Áron Szremkó and Judit Paksi for their contribution to building up the virtual globe. The 3D models would not have been completed without their work.

\section{References}

Anson, R. W. and Gutsell, B. V. (1989). The Award of Prizes, ICA Newsletter, Number 14, October 1989, pp. 7-8.

Gede, M. (2015). Novel Globe Publishing Techniques Using WebGL. e-Perimetron, 10(2), pp. 87-93.

Gede, M. and Márton, M. (2009). Globes on the Web Technical Background and First Items of the Virtual Globes Museum. In: Gartner, G., Ortag, F. [Editors]: Cartography in Central and Eastern Europe. Springer, Berlin, Heidelberg, pp. 279-290. https://doi.org/10.1007/978-3-642-03294-3_18

Gede, M. and Ungvári, Zs. (2011). Blurring Boundaries Between Real and Digital/Virtual Globes - Creating virtual globes from real ones and vice versa. In: Buchroithner, M. [Editor]: True-3D in Cartography. Springer, Berlin, Heidelberg, pp. 187-198. https://doi.org/10.1007/978-3-642-12272-9_12

Kartográfiai Vállalat [Cartographia] (1985). Nagy Világatlasz [Great World Atlas], Budapest, 424 pp.

Kovács, P. and Márton, M. (1989). Globes of the Cartographia. In: Csáti, E. [Editor]: Hungarian Cartographical Studies, Hungarian National Committee, Internat. Cartogr. Assoc., Budapest; pp. 61-69. http://azarus.elte.hu/hun/dolgozo/marton/globus/aglobe s.htm

Márton, M. and Kővári, J. (1984). Jelentés a 820013 munkaszámú kutatási feladat (A tengerfenék-domborzat ábrázolásának vizsgálata) végrehajtásáról (Kézirat) [Report on the No. 820013 research, "Study on the representation of seafloor relief" (Manuscript)], Kartográfiai Vállalat, Budapest, 1+95 pp.

Virtual Globes Museum [VGM] (2007-). VGM ID: 8, 9, 10, 41, 43, 66, 67, 68, 84, 154, 155, 156, Eötvös Loránd University, Institute of Cartography and Geoinformatics, Budapest. http://terkeptar.elte.hu/vgm

\section{Appendix}

The virtual globes referenced in the paper with their VGM ID can be accessed via the following links:

http://terkeptar.elte.hu/vgm/2/?lang=en\&show=globe\&wt $\mathrm{f}=8 \& \mathrm{wf}=\mathrm{id} \&$ ord $=\mathrm{id} \& \mathrm{id}=8$ [ID 8] http://terkeptar.elte.hu/vgm/2/?lang=en\&show=globe\&wt $\mathrm{f}=8 \& \mathrm{wf}=\mathrm{id} \&$ ord $=\mathrm{id} \& \mathrm{id}=9$ [ID 9]

http://terkeptar.elte.hu/vgm/2/?lang=en\&show=globe\&wt $\mathrm{f}=8 \& \mathrm{wf}=\mathrm{id} \&$ ord $=\mathrm{id} \& \mathrm{id}=10$ [ID 10]

http://terkeptar.elte.hu/vgm/2/?lang=en\&show=globe\&wt $\mathrm{f}=8 \& \mathrm{wf}=\mathrm{id} \&$ ord $=\mathrm{id} \& \mathrm{id}=41$ [ID 41]

http://terkeptar.elte.hu/vgm/2/?lang=en\&show=globe\&wt $\mathrm{f}=8 \& \mathrm{wf}=\mathrm{id} \&$ ord $=\mathrm{id} \& \mathrm{id}=43$ [ID 43]

http://terkeptar.elte.hu/vgm/2/?lang=en\&show=globe\&wt $\mathrm{f}=8 \& \mathrm{wf}=\mathrm{id} \&$ ord $=\mathrm{id} \& \mathrm{id}=66$ [ID 66]

http://terkeptar.elte.hu/vgm/2/?lang=en\&show=globe\&wt $\mathrm{f}=8 \& \mathrm{wf}=\mathrm{id} \&$ ord $=\mathrm{id} \& \mathrm{id}=67$ [ID 67]

http://terkeptar.elte.hu/vgm/2/?lang=en\&show=globe\&wt $\mathrm{f}=8 \& \mathrm{wf}=\mathrm{id} \&$ ord $=\mathrm{id} \& \mathrm{id}=68$ [ID 68]

http://terkeptar.elte.hu/vgm/2/?lang=en\&show=globe\&wt $\mathrm{f}=8 \& \mathrm{wf}=\mathrm{id} \&$ ord=id\&id=84 [ID 84]

http://terkeptar.elte.hu/vgm/2/?lang=hu\&show=globe\&wt $\mathrm{f}=8 \& \mathrm{wf}=\mathrm{id} \&$ ord $=\mathrm{id} \& \mathrm{id}=154$ [ID 154]

http://terkeptar.elte.hu/vgm/2/?lang=hu\&show=globe\&wt $\mathrm{f}=8 \& \mathrm{wf}=\mathrm{id} \&$ ord $=\mathrm{id} \& \mathrm{id}=155$ [ID 155]

http://terkeptar.elte.hu/vgm/2/?lang=hu\&show=globe\&wt $\mathrm{f}=8 \& \mathrm{wf}=\mathrm{id} \&$ ord $=\mathrm{id} \& \mathrm{id}=156$ [ID 156] 